\title{
On- and off-design thermodynamic analysis of a hybrid polar solar thermal tower power plant
}

\author{
Rosa P. Merchán | María J. Santos | Alejandro Medina ${ }^{\circledR}$ | \\ Antonio Calvo Hernández
}

Department of Applied Physics and IUFFYM, University of Salamanca,

Salamanca, Spain

\section{Correspondence}

Alejandro Medina, Department of Applied

Physics and IUFFYM, University of

Salamanca, Salamanca, Spain.

Email: amd385@usal.es

\section{Funding information}

Banco Santander; Consejería de Educación, Junta de Castilla y León, Grant/Award Number: SA017P17;

University of Salamanca

\section{Summary}

Concentrated solar power (CSP) is one challenging renewable technology for the production of electricity. Within this concept central receiver solar plants combined with gas turbines are being investigated because of their promising efficiencies and reduced water consumption. Hybrid plants incorporate a combustion chamber in such a way that in periods of low solar irradiance power output can be kept approximately constant and so, electricity production is predictable. An integrated, non-complex solar thermodynamic model of a hybrid gas turbine solar plant is developed employing a reduced number of parameters with a clear physical meaning. The solar subsystem is modeled in detail, taking into account the main heliostats field losses factors as cosine effect, blocking and shadowing, or attenuation. An heliostat field with polar symmetry together with a cavity receiver are considered. The model is implemented in our own software, developed in Mathematica language, considering as reference SOLUGAS solar field (Seville, Spain). Heliostats field configuration is determined for the design point and its associated efficiency is computed. First, an on-design analysis is performed for two different working fluids (dry air and carbon dioxide), for recuperative and non-recuperative modes. A pre-optimization process is carried out regarding the pressure ratio of the gas turbine for different configurations. Some significant efficiency and power rises can be obtained when pressure ratio is adapted for each specific configuration and working fluid. Maximum achievable plant overall efficiency is 0.302 for both fluids in the recuperative mode, taking a pressure ratio of 7 for dry air and 16 for carbon dioxide. In non-recuperative configurations maximum overall efficiency is obtained for dry air, about 0.246 . Moreover, a dynamic study is performed for four representative days of each season. Then, efficiencies and solar share are plotted against time. In addition, fuel consumption and greenhouse emissions are computed for all seasons.

\section{K E Y W O R D S}

concentrated solar power, dynamic analysis, gas turbines, overall plant efficiency, solar field efficiency, tower power plants 


\section{INTRODUCTION}

The current energetic paradigm for the planet presents lots of challenges worldwide. On one side, the climate change hazard related to pollutant greenhouse emissions produced in combustion of fossil fuels together with the finitude of these fossil resources make necessary a real change in energy paradigm towards cleaner and more reliable energy sources. On the other side, population and energy demand growth emphasize the necessity of new power production means.

Concentrated solar power (CSP) plants could fulfill to a good extent these requirements. These systems concentrate solar energy for heating a fluid, which develops a thermodynamic cycle. ${ }^{1}$ Within these systems, plants working under Brayton cycles present all the advantages of gas turbines. Namely, they require reduced amounts of water, which is important for locations with high solar resources, and efficiency rates are high due to large working temperatures. Moreover, they stand out due to their flexibility, reliability, and scalability. ${ }^{2}$ Another key factor is the possibility to guarantee an approximately constant power output through hybridization. ${ }^{3}$ Hybrid plants incorporate a combustion chamber and a control system that allows a constant turbine inlet temperature. This in turn leads to a stable power production, removing solar irradiance fluctuations and affording correct night performance. ${ }^{4}$ However, these systems are not totally emissions free, usually natural gas or biogas are burnt. Hybridization is thus an alternative to thermal storage with molten salt tanks, as several commercial plants, mostly running a Rankine cycle do. ${ }^{5,6}$ In this case upper temperatures are smaller than in gas turbines. In the last years, several research projects and some prototypes of hybrid thermosolar Brayton plants have been carried out. A key outcome is that the technology is feasible, but competitive prices must be reached. ${ }^{7}$ Therefore, a search for better output records as power output and efficiency results essential. This is the main objective of the present work.

During the last few years considerable efforts have been devoted to analyze the possibilities of supercritical $\mathrm{CO}_{2}$ as working fluid for such thermosolar Brayton plants ${ }^{8}$ or in other applications of gas turbines. ${ }^{9}$ This is because of expected high efficiencies, compactness, and capital cost reduction..$^{10}$ Although several thermodynamical and technical studies were conducted, ${ }^{11,12}$ there is still uncertainty on the design and efficiencies of turbomachinery components working at supercritical conditions. ${ }^{13}$ On the contrary, there are scarce studies on $\mathrm{CO}_{2}$ or other working fluids, different from air, working at subcritical conditions. ${ }^{14}$ Particularly, looking for optimum design pressure ratios adequate for the typical turbine inlet temperatures of thermosolar plants is a field that deserves investigation.
The work will be focused on the performance of the whole thermosolar plant, including all the subsystems that constitute it. Plant performance analysis will include, not only thermodynamic efficiency, but also solar share, fuel conversion efficiency, and a survey on the working temperature of the solar receiver, which is substantially influenced by the working fluid.

In this paper it is presented a framework to calculate the output parameters for the whole plant including a model for each subsystem (solar and power unit). ${ }^{14}$ On one hand it is detailed enough to obtain precise numerical results but, on the other hand, it is not too intricate and the number of parameters for the whole system is not too high. This makes easier to identify the main losses in the system and to get hints about the ways with more room for optimization. A novel issue in the model is that it allows for the analysis of heliostat fields with polar symmetry, suitable for central towers with cavity receivers. ${ }^{15,16}$ It is more usual to find in the literature studies about central towers with cylindrical receivers and so, approximately circular symmetry for the field (surround fields). ${ }^{17}$ In this work we are interested in plants with cavity receivers, able to operate at very high temperatures. This is specially interesting for Brayton-like thermodynamic cycles where temperatures above $1000 \mathrm{~K}$ ensure good efficiencies. To the best of our knowledge there is only one pre-commercial scale plant of this type (cavity receiver and hybrid Brayton cycle). It is called SOLUGAS project and was developed by the company Abengoa Solar, near Seville (Spain). ${ }^{18,19}$ Basic dimensions and design parameters will be assumed from this prototype plant and an optimization analysis considering different working fluids, plant configurations, and pressure ratios for the turbine will be analyzed. The analysis is divided into two parts: first, a pre-optimization is performed at on-design conditions, and second, an off-design analysis for particular days of any season is developed.

\section{2 | OVERALL PLANT MODEL}

A solar central tower plant hybridized with a combustion chamber and linked to a closed gas turbine is considered as system under study. The combustion chamber allows for a stable production of power output. The system is depicted in Figure 1, where the three subsystems composing the overall system can be observed: solar part, combustion chamber, and heat engine. Sun radiation is collected by a polar heliostat field, which concentrates and reflects it into a cavity receiver atop the tower. Then, the working fluid takes advantage of the solar heat and it is also heated by the combustion chamber until the desired turbine inlet temperature if necessary. Turbine 


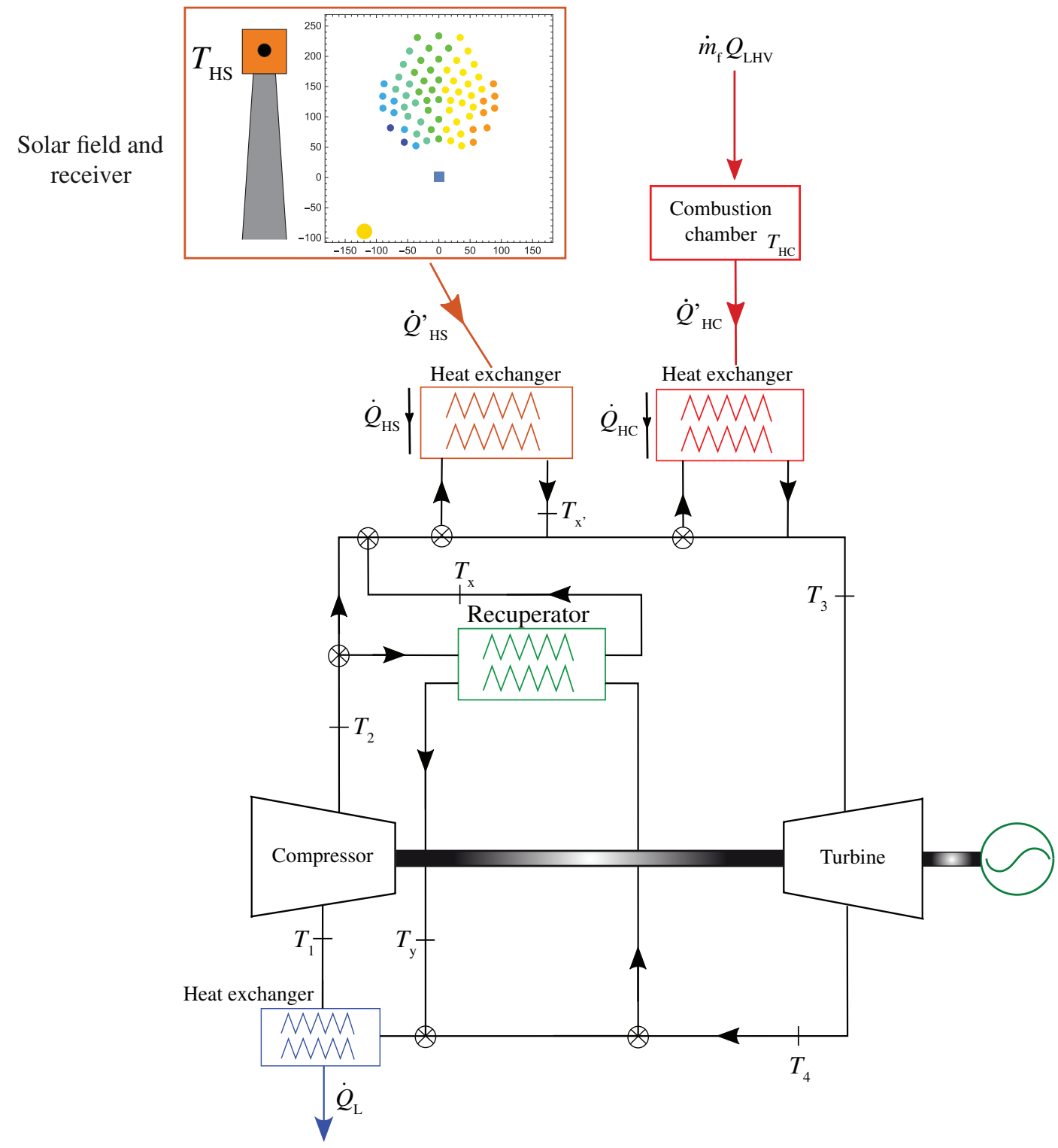

F I G U R E 1 Scheme of the considered thermosolar plant, constituted by three different subsystems: solar subsystem, combustion chamber, and heat engine itself [Colour figure can be viewed at wileyonlinelibrary.com]

inlet temperature, $T_{3}$, is considered as a fixed input parameter.

The overall thermal efficiency of the system, $\eta$, is defined in the usual thermodynamic way as the quotient between the power output, $P$, and the total energy input into the system, $\eta=P /\left(G A_{a}+\dot{m}_{f} Q_{L H V}\right)$, where $G$ represents the direct normal irradiance; $A_{a}$, the aperture area; $\dot{m}_{f}$, the fuel mass flow in the combustion chamber; and $Q_{L H V}$, the fuel lower heating value. It is feasible to write $\eta$ as a combination of the efficiencies of all the subsystems: $\eta_{h}$, heat engine efficiency, $\eta_{s}$, solar subsystem efficiency (including heliostat field and receiver), $\eta_{c}$, combustion efficiency, and the effectivenesses of the heat exchangers between them, $\varepsilon_{H S}$ and $\varepsilon_{H C}$. In the equation it appears also the solar share or fraction of energy input coming from the solar resource, $f$. Definitions and explicit calculations to obtain $\eta$ can be found in recent works by our group. ${ }^{14,20,21}$

$$
\eta=\eta_{h} \eta_{s} \eta_{c}\left[\frac{\varepsilon_{H S} \varepsilon_{H C}}{\eta_{c} f \varepsilon_{H C}+\eta_{s}(1-f) \varepsilon_{H S}}\right]
$$

Overall plant efficiency is thus obtained as the result of the integration of main plant subsystems in a clear way. This approach is devoted to identify main efficiency bottlenecks and, so, to propose improvements for new plant designs. Next the submodels for each component efficiency are summarized.

The thermodynamic model for the closed Braytonlike cycle in order to obtain $\eta_{h}$ considers a working gas 
with temperature dependent specific heats and mass flow $\dot{m}$. For modeling purposes the cycle is considered as closed although in real applications (when air is the working fluid) the cycle uses to be open. But one of the objectives of this work is the performance comparison between air and subcritical $\mathrm{CO}_{2}$ and for the latter the cycle should be closed. Thus, the comparison between both fluids, to obtain meaningful results, has to be done from a closed cycle scheme.

The working fluid mass flow enters the compressor at a temperature $T_{1}$ (following the notation of Figure 1). The compressor is considered as non-ideal and its isentropic efficiency is denoted as $\varepsilon_{c}$. Then, it is heated up in three steps. First by means of a recuperator with effectiveness $\varepsilon_{r}$. The temperature of the gas at the recuperator exit is denoted as $T_{x}$. In the case of a non-recuperative layout $T_{x}=T_{2}$. Second, by the solar heat received at the solar field and transferred to the fluid in the receiver (thermodynamically the receiver is assumed as a heat exchanger with effectiveness $\left.\varepsilon_{H S}\right)$. At the receiver exit gas temperature is $T_{x^{\prime}}$. If necessary (by night or when direct normal irradiance is poor) a combustion chamber ensures that the temperature of the fluid at turbine inlet is always $T_{3}$. The combustion chamber, as the solar receiver, it is also considered as a non-ideal heat exchanger with effectiveness $\varepsilon_{H C}$. Also losses in the combustion chamber itself associated to non-perfect combustion are accounted for. Combustion efficiency is denoted as $\eta_{c}$. The expander is taken as non-isentropic and it is characterized by its isentropic efficiency, $\varepsilon_{t}$. The temperature at the turbine exit is called $T_{4}$. Then, the hot gas releases heat through the recuperator to the fluid at the compressor exit. Finally, the cycle is closed by releasing heat to the ambient at temperature $T_{L}$ in order to keep the compressor inlet temperature at $T_{1}$. The corresponding heat exchanger has an effectiveness $\varepsilon_{L}$. It is feasible to express all cycle temperatures in terms of those of the solar receiver, $T_{H S}$, and the combustion chamber, $T_{H C}$, the compressor pressure ratio, $r_{p}$, and all the parameters referred to cycle irreversibilities. Then, heat inputs from the solar collector, $\dot{Q}_{H S}$, and the combustion chamber, $\dot{Q}_{H C}$, are expressed in terms of the (temperature dependent) constant pressure specific heat of the working gas, $c_{p}(T)$, as:

$$
\begin{aligned}
& \left|\dot{Q}_{H S}\right|=\int_{T_{x}}^{T_{x^{\prime}}} c_{p}(T) d T \\
& \left|\dot{Q}_{H C}\right|=\int_{T_{x^{\prime}}}^{T_{3}} c_{p}(T) d T
\end{aligned}
$$

The total heat input is $\left|\dot{Q}_{H}\right|=\left|\dot{Q}_{H S}\right|+\left|\dot{Q}_{H C}\right|$ and the heat released to the ambient is

$$
\left|\dot{Q}_{L}\right|=\int_{T_{1}}^{T_{y}} c_{p}(T) d T
$$

and so, $P=\left|\dot{Q}_{H}\right|-\left|\dot{Q}_{L}\right|$ and $\eta_{h}=P /\left|\dot{Q}_{H}\right|$. Further details on the calculations can be found in Ref. ${ }^{14}$ This model for the Brayton cycle allows to estimate the corresponding efficiency, $\eta_{h}$, power output and any other parameter as cycle temperatures in a precise but not computationally expensive way, as will be shown in Sec. 3 .

To calculate the efficiency of the solar subsystem, $\eta_{S}$, two kinds of losses have to be taken into account: the optical losses in the reflection of solar energy from the heliostats to the receiver at the top of the tower, $\eta_{0}$, and the thermal losses in the receiver. The second are calculated as in, ${ }^{14,22}$ including convective, conductive, and radiation losses:

$$
\eta_{S}=\eta_{0}-\frac{1}{G C}\left[\alpha \sigma\left(T_{H S}^{4}-T_{L}^{4}\right)+\bar{U}_{L}\left(T_{H S}-T_{L}\right)\right]
$$

where $C$ is the concentration ratio, $\alpha$ refers to the emissivity of the receiver surface, $\sigma$ is the Stefan-Boltzmann constant, $\bar{U}_{L}$ corresponds to an overall conduction and convection heat transfer coefficient, $T_{H S}$ is the solar collector temperature, and $T_{L}$ represents the ambient temperature.

The optical efficiency of the heliostat field, $\eta_{0}$, is computed in detail. Hence, solar field is divided into different rows and, in each row, heliostats are placed considering the space they can occupy during the solar tracking together with a safety distance. ${ }^{23}$ Each heliostat has a different efficiency, which also varies with the solar hour and the season of the year, because of its particular location. This efficiency of each heliostat is considered as a product of different losses factors, as it is shown in Equation (6).

$$
\eta_{\mathrm{hel}, \mathrm{i}}=\cos \omega \cdot f_{\mathrm{b}, \mathrm{sh}} \cdot f_{\mathrm{sp}} \cdot f_{\mathrm{at}} \cdot \rho
$$

The primary contribution to this optical efficiency is the cosine effect, $\cos \omega^{24}$ which accounts for the cosine of the incident angle of the Sun radiation in the heliostat surface. It is computed by means of a study of the Sunheliostat-receiver geometry. ${ }^{25}$ Blocking effect measures the amount of lost energy when a fraction of the radiation coming from a back heliostat reflects in an ahead one. In a similar way, shadowing effect comprehends lost energy due to the shadow projected by a heliostat on another one. Both effects are included in the blocking and shadowing factor, $f_{\mathrm{b}, \mathrm{sh}}$, which is assumed as a constant factor to avoid a high computational cost, following the works by Collado et al. ${ }^{25,26}$ The factor, $\rho$, defines the amount of solar radiation that each heliostat can reflect towards the receiver depending on the materials, coating, 
cleanliness, and curvature. ${ }^{26}$ When solar radiation travels towards the receiver, ambient air molecules absorb a fraction. Such attenuation factor, $f_{\text {at }}$, results in another energy $\operatorname{loss}^{26}$ depending on the distance of a particular heliostat to the receiver. And, the last important energy loss source is the spillage factor, $f_{\mathrm{sp}}$, related to solar radiation not aiming the absorption area of the receiver, but closer zones. The model by Collado et al. is assumed. ${ }^{26} \mathrm{In}$ this model spillage factor depends on the receiver dimensions, heliostat area, the effective dispersion of the sun shape on the receiver plane, heliostat tracking, and surface errors. So, the spillage factor depends on each heliostat. With all these assumptions, the efficiency of each heliostat is calculated and then, that of the whole field, $\eta_{0}$, as the simple averaged efficiency of all heliostats. The thermodynamic and optical models were implemented in Mathematica.

\section{3 | NUMERICAL CONSIDERATIONS}

SOLUGAS project (Seville, Spain) ${ }^{18,19}$ is the first prototype at a pre-commercial scale where a standard gas turbine is hybridized with a polar heliostat field through a cavity receiver. It incorporates a standard gas turbine, Caterpillar Mercury 50, but with extensive modifications. ${ }^{27}$ The standard Mercury 50 gas turbine is recuperated and single shaft, with an axial compressor and an ultra lean premix combustion system. It guarantees NOx emissions below $5 \mathrm{ppm}$ and $\mathrm{CO}$ and UHC below $10 \mathrm{ppm}$. It was designed for combined heat and power applications and also for intermediate peaking applications. In the SOLUGAS project the turbine was modified to operate driven by solar energy. Details on the modifications were not made explicit but at least the recuperator was substituted by the solar receiver, a by-pass between the receiver inlet and outlet pipes was placed (to control receiver air mass flow and to allow directing the pressurized air directly from the compressor to the combustion chamber) and control systems modified. Also higher temperatures in the combustion system were surveyed and protections re-designed. Because of the absence of specific data for the modified turbine, the validation of the gas turbine model developed in this work was done on the original turbine design. Details can be found in previous publications ${ }^{14,28}$ and so, only a brief summary is sketched here. Table 1 contains the main model parameters taken in order to validate the gas turbine Mercury 50 by comparing our model predictions with the measures at the real turbine. Ambient temperature at design conditions was set at $288 \mathrm{~K}$, pressure ratio is 9.9 and air mas flow is $17.9 \mathrm{~kg} / \mathrm{s} .{ }^{27}$ Assumed isentropic efficiencies of the compressor and turbine, heat exchangers effectivenesses and pressure losses parameters are shown in the table. Relative deviations among model outputs and real measures barely exceed $4 \%$. Main temperatures of the gas during the cycle are also in the table. Predicted efficiency is 0.398 , about $3.27 \%$ over measured efficiency and predicted power output is 4.77 , about $3.66 \%$ over measured power. More details about validation can be found in. ${ }^{14,28}$ As the focus of this work is placed on the performance of the overall thermosolar plant, those differences are assumed as reasonable.

After validation, gas turbine performance is analyzed in Figure 2 in terms of three essential design parameters: pressure ratio, $r_{p}$, working gas mass flow, $\dot{m}$, and turbine inlet temperature, $T_{3}$. From panel (a) it is concluded that power unit efficiency does not depend on the mass flow (turbine size), but pressure ratio has a definite importance. Efficiencies about 0.4 could be achieved for pressure ratios roughly between 4 and 9 and are, as expected, independent of the working fluid mass flow. Comparing with the design parameters of the turbine Mercury 50 (see the circle in Figure 2A) larger efficiencies could be obtained by reducing the experimental pressure ratio,

T A B L E 1 Main irreversibility parameters considered to validate the gas turbine Caterpillar Mercury 50 used in the project SOLUGAS at design conditions. ${ }^{27}$ Ambient temperature was set at $288 \mathrm{~K}$, pressure ratio is 9.9 and air mas flow is $17.9 \mathrm{~kg} / \mathrm{s}^{27}$

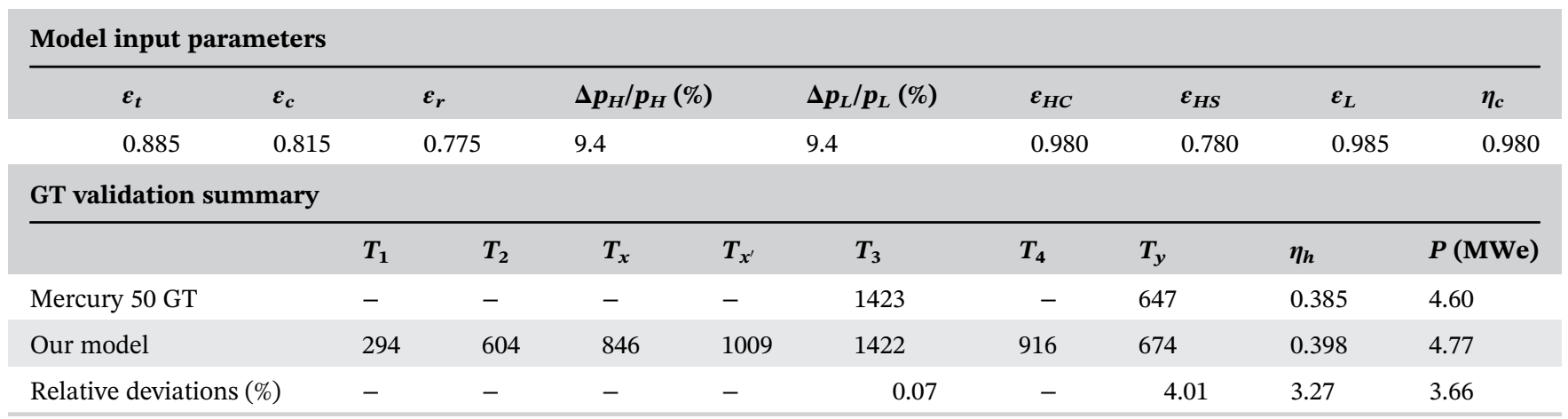

Note: All temperatures are expressed in $\mathrm{K}$. 
(A)

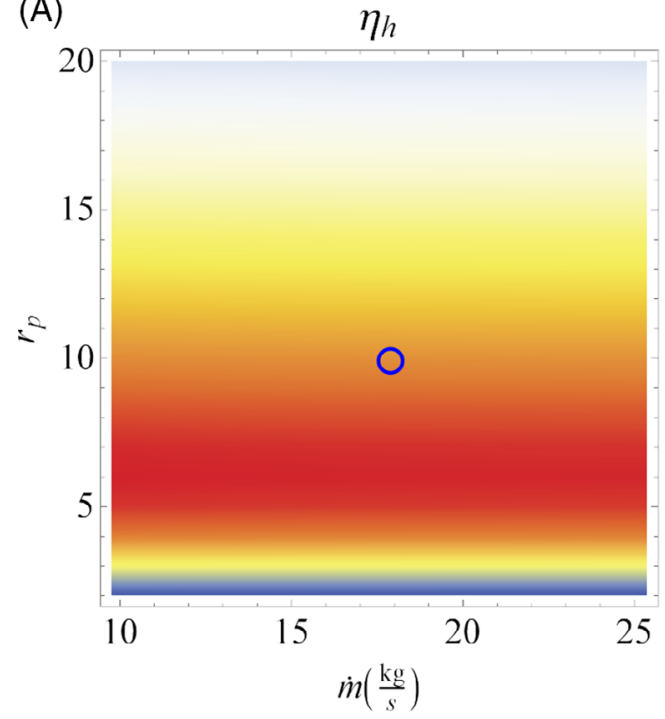

(C)

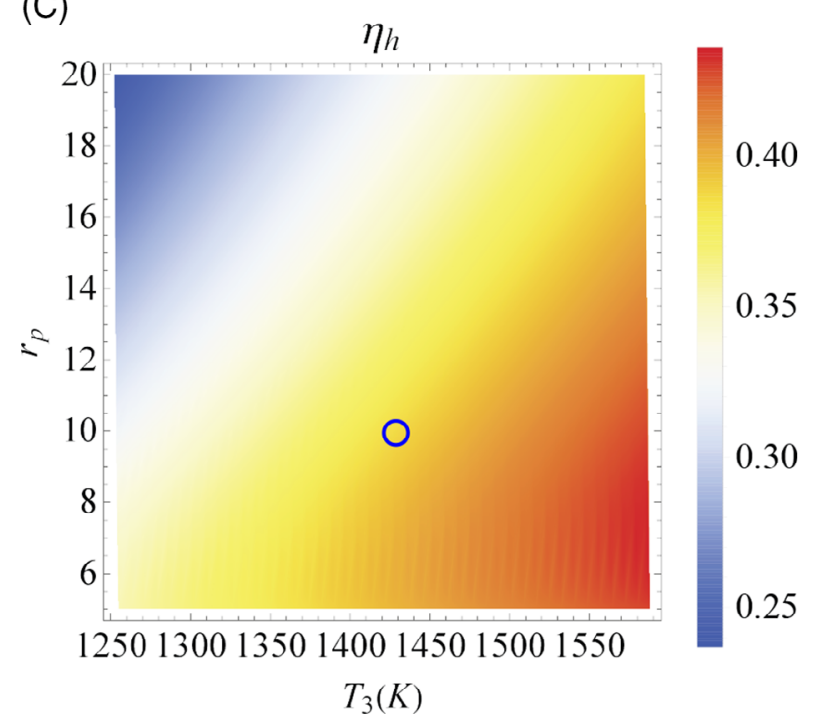

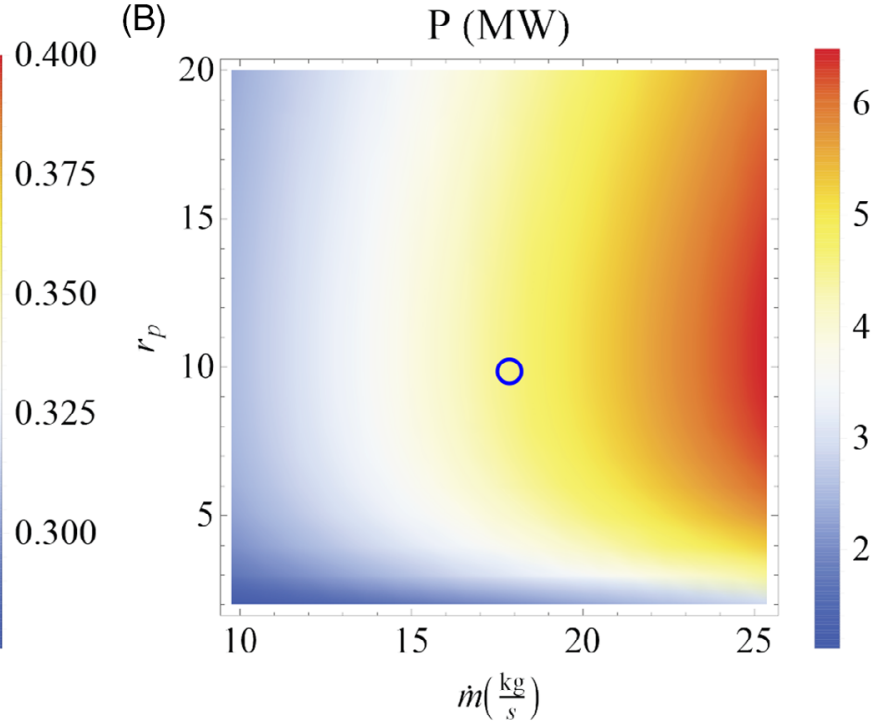

(D)

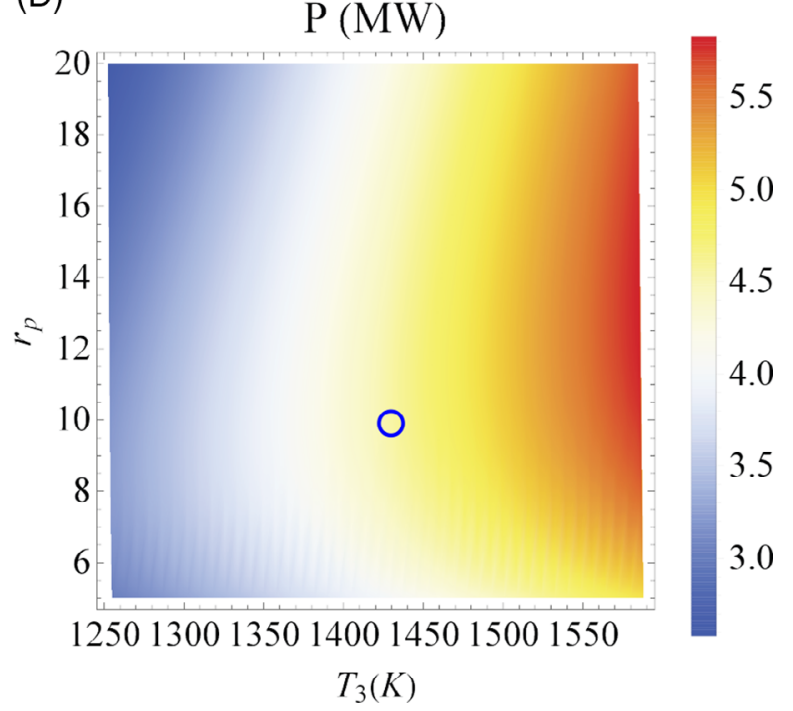

FI G URE 2 Density plots of the efficiency of the gas turbine as calculated from the developed model, $\eta_{h}$, and the corresponding power output, $P$, as functions of three key design parameters: pressure ratio, $r_{p}$; working fluid mass flow, $\dot{m}$; and turbine inlet temperature, $T_{3}$. Circles correspond to the design parameters of the turbine Mercury $50^{27}$ [Colour figure can be viewed at wileyonlinelibrary.com]

9.9, to slightly lower values (if other parameters keep constant). Power output (see Figure 2B) linearly increases with $\dot{m}$ and there is a wide interval for $r_{p}$ leading to alike power. In Figure $2 \mathrm{C}$ it is analyzed the evolution of $\eta_{h}$ simultaneously with $r_{p}$ and the turbine inlet temperature, $T_{3}$. Small values of pressure ratio and large values of $T_{3}$ lead to the best efficiencies. Nevertheless, $T_{3}$ is limited from a practical viewpoint because of metallurgical and cost reasons. Finally, power output (see Figure 2D) also increases with $T_{3}$ and the election of $r_{p}$ is not critical, for each value of $T_{3}$ there is a wide interval of pressure ratios with similar power outputs.

The most important parameters of the solar field size and those used to estimate the efficiency of the solar subsystem are contained in Table 2. Design point with respect to solar conditions is taken as June $20^{\text {th }}, 2013$, with a direct solar irradiance $G=760 \mathrm{~W} / \mathrm{m}^{2}$, and ambient temperature $T_{L}=296.5 \mathrm{~K}$. For off-design conditions meteorological data were taken from Meteosevilla database for the location of SOLUGAS ${ }^{29,30}\left(37^{\circ} 26^{\prime} 23^{\prime \prime}\right.$ North latitude, $6^{\circ} 17^{\prime} 4^{\prime \prime}$ West longitude). Figure 3 contains the daily evolution of direct normal irradiance, $G$, and ambient temperature, $T_{L}$, at SOLUGAS location. Comparing the limit cases, winter and summer, the picture shows that maximum $G$ in summer reaches almost $900 \mathrm{~W} / \mathrm{m}^{2}$ and there are about 12 hours with acceptable irradiance. On the opposite, maximum $G$ in winter is approximately $500 \mathrm{~W} / \mathrm{m}^{2}$ and sun hours about 8 . The oscillatory profiles of ambient temperature are shown in the bottom of Figure 3. Globally, summer days are hot and winter days 
TABLE 2 Table of parameters values employed in the simulations (adapted from SOLUGAS prototype plant ${ }^{19}$ )

\begin{tabular}{|c|c|}
\hline Parameter & Value \\
\hline $\begin{array}{l}\text { Height of the tower supporting the } \\
\text { receiver }\end{array}$ & $65 \mathrm{~m}$ \\
\hline Diameter of the receiver & $5 \mathrm{~m}$ \\
\hline Number of heliostats & 70 \\
\hline Height of each heliostat & $11.01 \mathrm{~m}$ \\
\hline Width-height ratio of each heliostat & 1.0 \\
\hline Concentration ratio $(C)$ & 432.443 \\
\hline Focusing & $\begin{array}{l}\text { Simple (receiver } \\
\text { center) }\end{array}$ \\
\hline $\begin{array}{l}\text { Separation distance between adjacent } \\
\text { heliostats }\end{array}$ & $3.303 \mathrm{~m}$ \\
\hline Minimum radius of the heliostat field & $64 \mathrm{~m}$ \\
\hline Blocking and shadowing factor $\left(f_{\mathrm{b}, \mathrm{sh}}\right)$ & 0.95 \\
\hline Actual mirror reflectivity $(\rho)$ & 0.836 \\
\hline SD due to Sun shape & $2.51 \mathrm{mrad}$ \\
\hline SD due to surface errors & $0.94 \mathrm{mrad}$ \\
\hline SD due to tracking errors & $0.63 \mathrm{mrad}$ \\
\hline Receiver emissivity $(\alpha)$ & 0.1 \\
\hline $\begin{array}{l}\text { Overall convection and conduction heat } \\
\text { transfer losses }\left(\bar{U}_{L}\right)\end{array}$ & $5 \mathrm{~W} /\left(\mathrm{m}^{2} \mathrm{~K}\right)$ \\
\hline
\end{tabular}

are warm, not too cool temperatures are reached. Afternoon temperature in summer is quite high, around $305 \mathrm{~K}$ and $20 \mathrm{~K}$ below in winter. Minimum temperatures in winter are about 275 and in summer $15 \mathrm{~K}$ above.

Two operation modes are considered, nonrecuperative and recuperative (in the recuperative case, recuperator effectiveness is taken as $0.775^{30}$ ). Also two working fluids at subcritical conditions are analyzed, air and carbon dioxide. The same mass flow was considered for both. Their specific heats were considered temperature dependent and taken from database Refprop. ${ }^{31}$ In the case of carbon dioxide an important effort has been devoted during the last years in the literature to analyze its possibilities in this kind of plants at supercritical conditions. ${ }^{32-34}$ It is expected a decrease of the compression work, and so, an increase of power output for a fixed heat input. Nevertheless, there is still a considerable uncertainty about the operation of the turbomachinery (compressors and turbines) at such supercritical conditions. Here, a comparison of carbon dioxide with air (both at subcritical conditions) in what refers to optimum pressure ratios, temperature levels, overall plant efficiencies, and other records is developed. The aim is to look for windows where, at the working temperatures of this type of thermosolar plants, optimized pressure ratios can lead
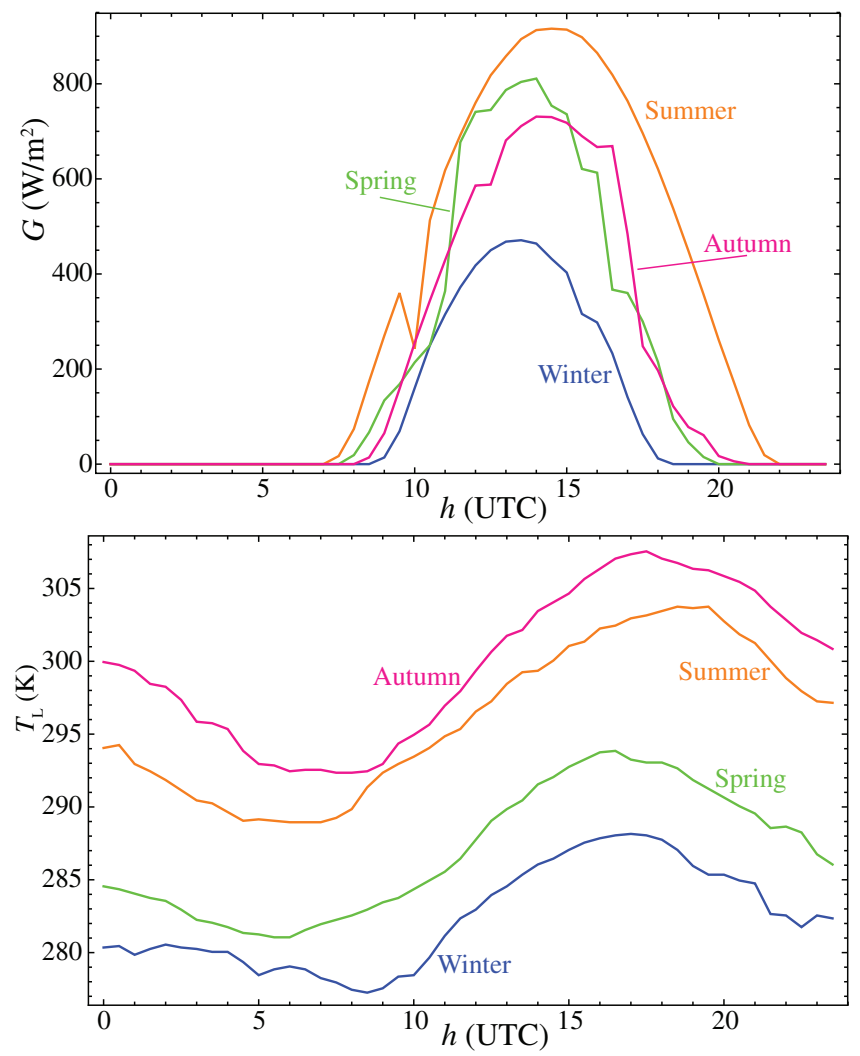

F I G URE 3 Evolution with time of direct normal irradiance, $G$, and ambient temperature, $T_{L}$, at Seville, Spain, for four representative days of each season during 2013: Winter (21st, December), Spring (21st, March), Summer (20th, June), and Autumn (21st, September). Curves are direct experimental data taken each 30 minutes, they are neither smoothed nor averaged ${ }^{29}$ [Colour figure can be viewed at wileyonlinelibrary.com]

to good output records for the whole plant. As it will be seen next, the temperatures of the gas at the turbine outlet greatly depend on the gas characteristics, and so the role of recuperation is important from the viewpoint of the working fluid. A schematic $p-T$ diagram of the Brayton cycles developed for both fluids is shown in Figure 4.

Figure 5 displays the Brayton cycles developed by the power unit for both fluids in the recuperative and nonrecuperative cases at the design point. Utmost temperatures (ambient temperature, $T_{1}$, and turbine inlet temperature, $T_{3}$ ) were fixed for all cases. As a brief summary from the figures, it should be remarked that temperatures after compression, $T_{2}$, are in both modes larger for air. This is the temperature at the entrance of the solar receiver in non-recuperative configurations (see Figure 5A). The temperature of the fluid at the receiver exit is $T_{x^{\prime}}$, that it is also quite larger for air. This suggests that the operation temperature of the solar receiver for air is larger than for subcritical $\mathrm{CO}_{2}$. This point is 
important from the viewpoint of the design and materials of the solar receiver. If its temperature is considered as a key design parameter (and actually it is because of economical reasons and also because losses at the receiver increase with its temperature) the influence of the working fluid should be checked from the perspective of the whole plant and not only from the viewpoint of the thermodynamic cycle developed by the power unit.

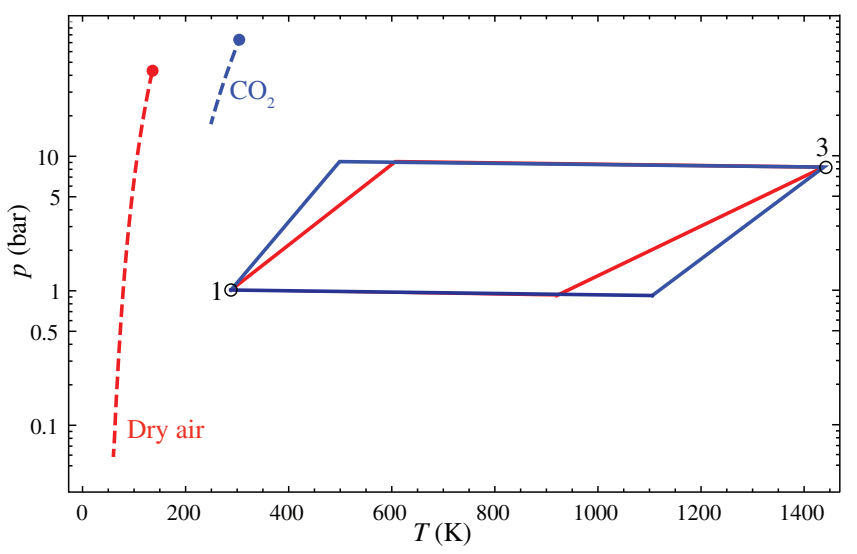

F I G URE 4 Semi-log $p-T$ plot of the base Brayton (subcritical) cycles for dry air and $\mathrm{CO}_{2}$ considered. Liquid-vapor coexistence lines for both fluids are represented as dashed lines and the critical points as filled circles. Compressor and turbine inlet states are shown as open circles [Colour figure can be viewed at wileyonlinelibrary.com]
From Figure 5B it is observed that the recuperator greatly increases the temperature of the gas entering the solar receiver, $T_{x}$ and so, its operating temperature for both fluids. Recuperative configurations require much higher temperatures for the receiver. Potential of $\mathrm{CO}_{2}$ for recuperation is larger than for air, because the temperature at the exit of the turbine, $T_{4}$, is higher for $\mathrm{CO}_{2}$. So, probably recuperated configurations increase the efficiency of the power unit itself but introduce undesired effects as the increase of the solar receiver operation temperatures (thus costs and heat transfer losses). With these considerations in mind, the next section is devoted to analyze simulations results, both at design conditions and also for off-design situations.

\section{4 | RESULTS}

\section{1 | On-design analysis and pre- optimization}

Design point fixes heliostat field configuration. Figure 6 shows the efficiency of each heliostat at the design point by a colour map. It can be observed that heliostats opposite to the Sun (marked as a yellow circle in Figure 6) present higher efficiencies, as stated by Stine and Geyer. ${ }^{35}$ Average heliostats efficiency at design conditions is $\eta_{0}=0.6891$ and overall plant efficiency, considering air as working fluid, is $\eta=0.2963$. The relatively low solar
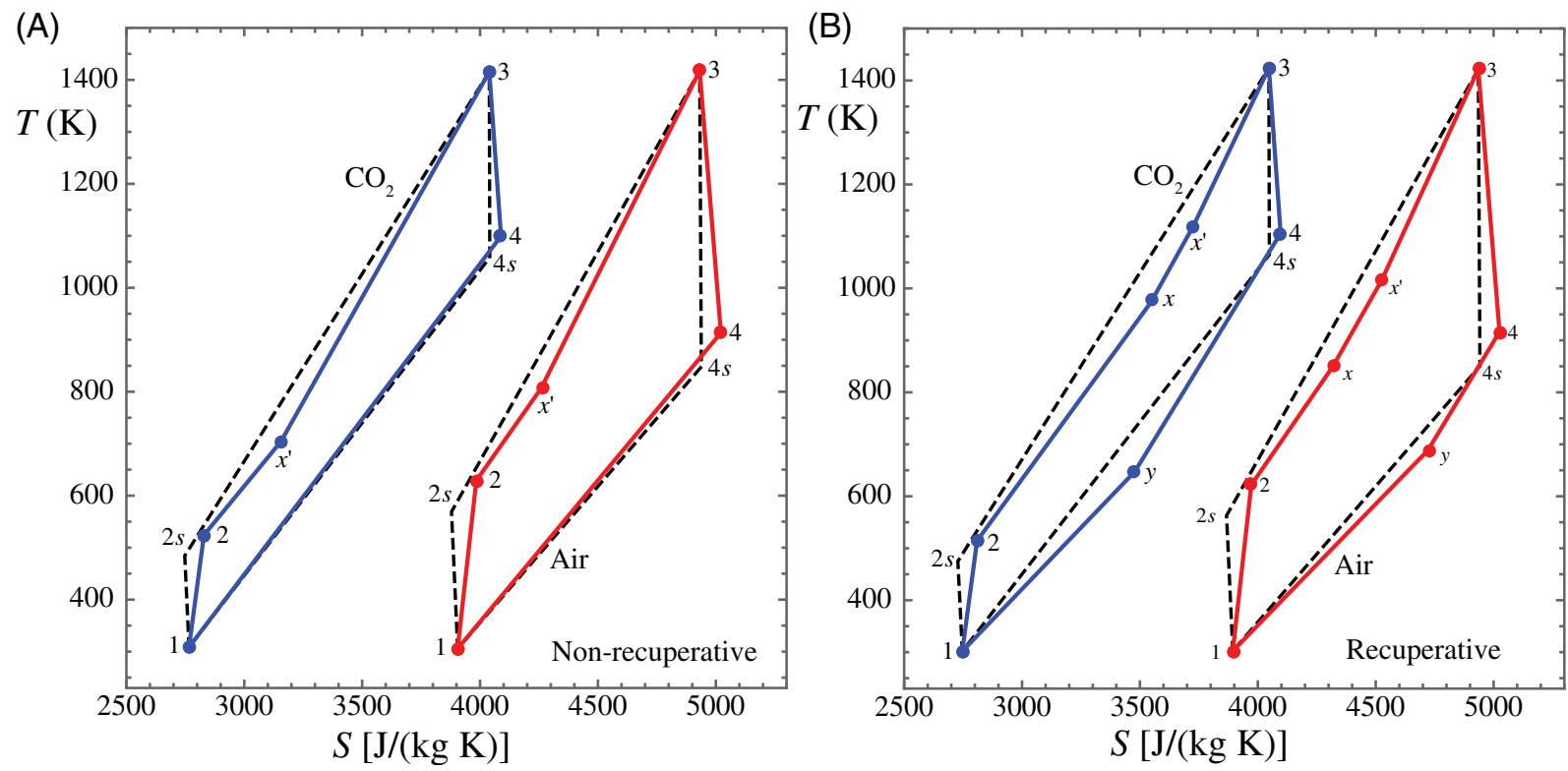

F I G U R E $5 T-S$ diagrams of the thermodynamic cycle developed by the power unit. Dashed lines represent the reversible ideal cases and solid ones the real cycles. Two working gases are considered: red color stands for air and blue for carbon dioxide. A, Non-recuperative cycles and B, recuperative ones. Notation corresponds to that of Figure 1. Without recuperation solar heat input corresponds to $2 \rightarrow x^{\prime}$ and with recuperation to $x \rightarrow x^{\prime}$ [Colour figure can be viewed at wileyonlinelibrary.com] 


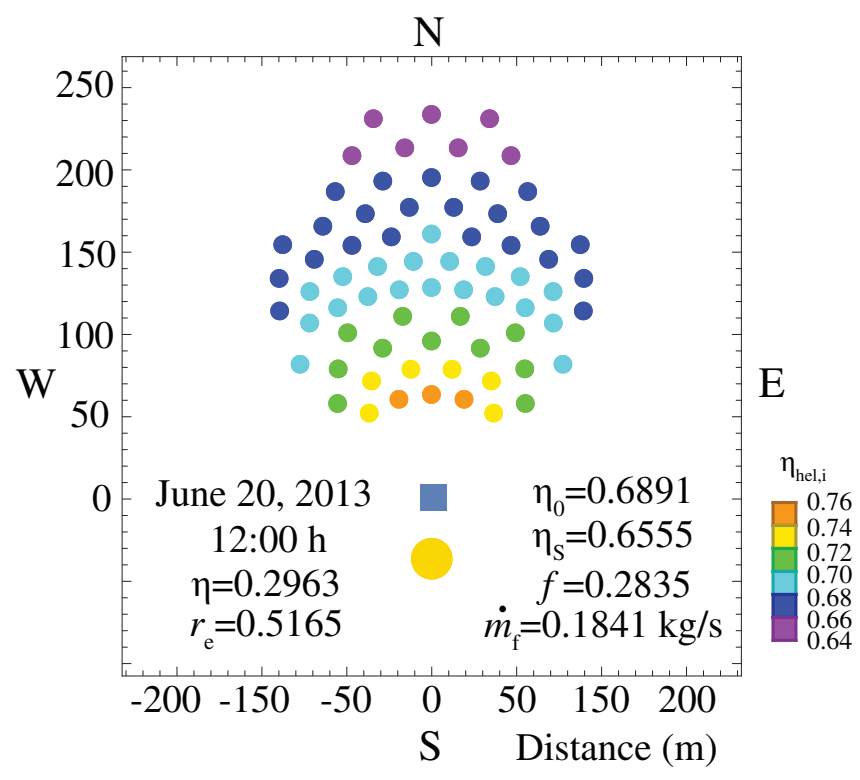

F I G U R E 6 Heliostats efficiencies in the field at design conditions. Some overall plant records are also shown: $\eta$, overall thermal efficiency; $r_{e}$, fuel conversion efficiency (net power output over heat input from the combustion chamber); $\eta_{0}$, field optical efficiency; $\eta_{s}$, solar subsystem efficiency (solar field and receiver); $f$, solar share, and $\dot{m}_{f}$, fuel consumption. Tower (blue square) and sun positions (yellow circle) are also depicted as a guide [Colour figure can be viewed at wileyonlinelibrary.com]

share, $f=0.2835$, indicates that field dimensions are small, so combustion is necessary to reach the target turbine inlet temperature.

From now on design conditions are considered, but the role played by the pressure ratio is analyzed in order to find optimum values for the considered fluids (subcritical air and carbon dioxide) and plant configurations (recuperative or non-recuperative). Overall plant efficiency, $\eta$, and power output, $P$, in terms of the pressure ratio are depicted in Figure 7. Overall efficiency is larger for recuperative configurations. When air is the working fluid $\eta$ displays a maximum around $r_{p} \simeq 7$ that leads to an efficiency about 0.30 , which is a remarkable value. For $\mathrm{CO}_{2}, \eta$ increases monotonically up to an asymptotic value similar to the maximum efficiency for air, 0.30 . $\mathrm{CO}_{2}$ allows to reach efficiencies around 0.30 only for high pressure ratios (above 10). For non-recuperative configurations, air provides considerable larger efficiencies that increase up to $\eta \simeq 0.25$ for pressure ratios above 15 . For $\mathrm{CO}_{2}$ it is difficult to reach efficiencies around 0.20 , even for high pressure ratios.

The power output, $P$ (Figure 7 , bottom), presents a maximum for air in both recuperative and nonrecuperative plant layouts. Maximum is located around $r_{p} \simeq 10$ (SOLUGAS design point). In the case of $\mathrm{CO}_{2}$ power increases monotonically with $r_{p}$ and does not
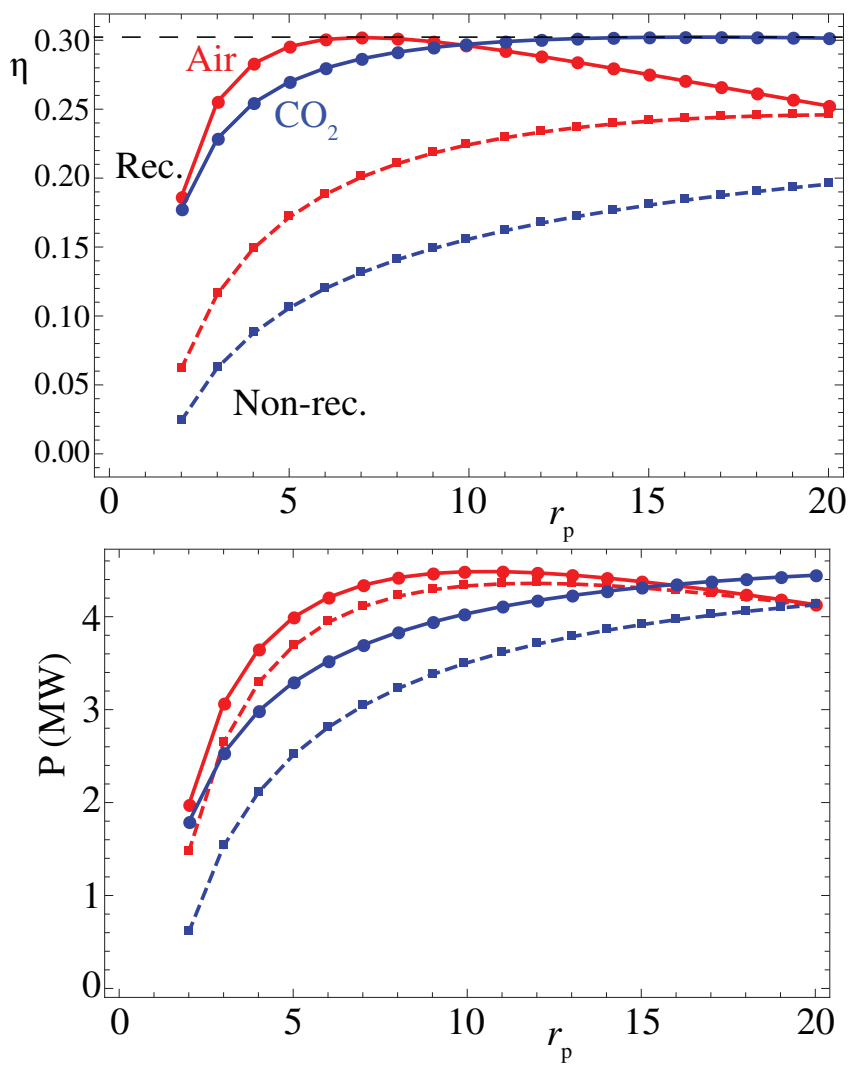

F I G U RE 7 Overall plant efficiency, $\eta$, and net power output, $P$, at design conditions as functions of the pressure ratio, $r_{p}$. Two working fluids for the gas turbine (air, red color and $\mathrm{CO}_{2}$, blue color) and recuperative (solid lines) and non-recuperative plant configurations (dashed) are considered [Colour figure can be viewed at wileyonlinelibrary.com]

reach a maximum in the surveyed interval. Power output is larger for the recuperative cases. Differences are larger for carbon dioxide. It is noteworthy that from a theoretical viewpoint, in the case of a reversible Brayton cycle developed by a gas with approximately constant specific heats, the power output (or work output) should be identical for recuperative and non-recuperative layouts. This is because recuperation implies an internal heat transfer, and the net difference between the heat input and heat release is not affected by the recuperator. But this is not true for irreversible Brayton cycles, where the intermediate temperatures $T_{2}$ and $T_{4}$ depend on cycle losses (explicit equations for those temperatures are written in the Appendix $\mathrm{A}$ of ${ }^{21}$ ). In the cases analyzed here, differences between the power output in recuperative and non-recuperative layouts are more important for $\mathrm{CO}_{2}$.

Parametric $\eta-P$ curves, obtained by eliminating $r_{p}$ between the curves $\eta=\eta\left(r_{p}\right)$ and $P=P\left(r_{p}\right)$, are represented in Figure 8. In the non-recuperative cases (dashed curves in the figure), curves are covered clockwise as pressure ratio increases. In the analyzed interval, 


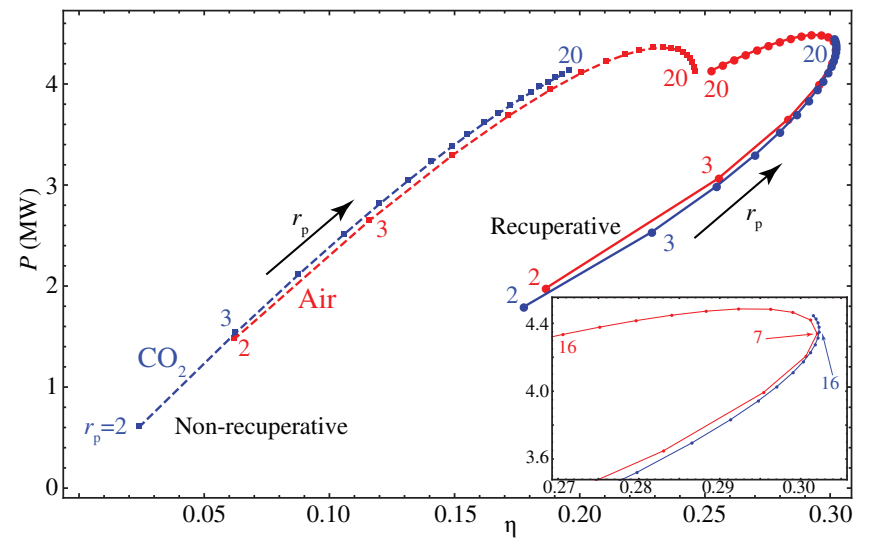

F I G URE 8 Parametric $\eta-P$ curves obtained by eliminating $r_{p}$ between the curves $\eta=\eta\left(r_{p}\right)$ and $P=P\left(r_{p}\right)$. The interval considered for $r_{p}$ is the same as in Figure 7, $r_{p} \in[2,20]$. Left curves (dashed) correspond to non-recuperative layouts. As $r_{p}$ increases the curve is covered clockwise. Right curves (recuperative) are covered in the opposite direction. Some numerical values of $r_{p}$ are shown as a guide. The inset shows a zoom of the recuperative curves. Maximum $\eta$ for air corresponds to $r_{p, \max }=7$ and to 16 for $\mathrm{CO}_{2}$ [Colour figure can be viewed at wileyonlinelibrary.com] $r_{p} \in[2,20]$, maximum power output and maximum efficiency are reached for air but not for $\mathrm{CO}_{2}$. In recuperative layouts curves are covered in the opposite direction. There is a clear displacement between the values $r_{p}$, max that maximize overall efficiency for both gases: maximum $\eta$ for air corresponds to $r_{p, \max }=7$ and to 16 for $\mathrm{CO}_{2}$ (see the inset in the figure). Thus, incorporating recuperation, maximum reachable efficiency is numerically very similar for both working fluids but at considerable lower pressure ratio values for air.

The fuel conversion efficiency, $r_{e}$, is defined as the ratio between the power output and the heat input from the combustion chamber (so with an economic cost). It is much larger for recuperative configurations (see Figure 9A). The maximum value is similar for air and $\mathrm{CO}_{2}$ (about 0.58 in both cases), but in the case of air it is more sensitive to the pressure ratio. As $r_{p}$ increases over approximately $5, r_{e}$ decreases more quickly for air than $\mathrm{CO}_{2}$. The solar share, $f$, is the fraction of heat input coming from the sun. For all the cases considered its numerical value is small (see Figure 9B). This means that the size of the heliostat field is relatively small for the
(A)

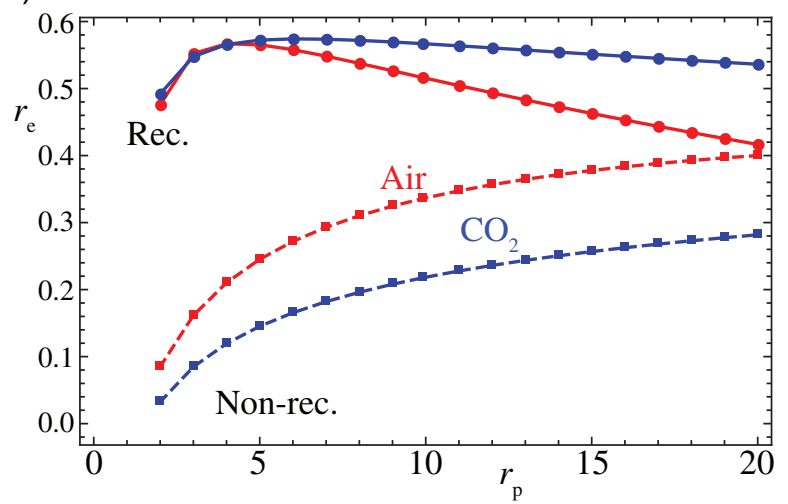

(C)

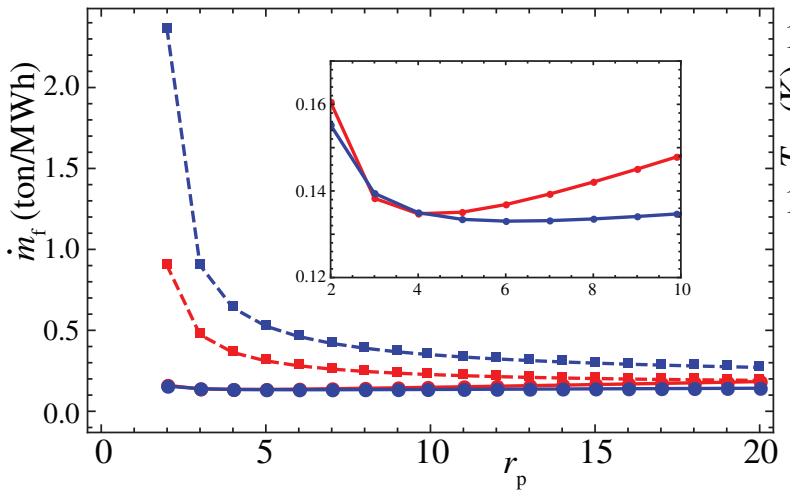

(B)

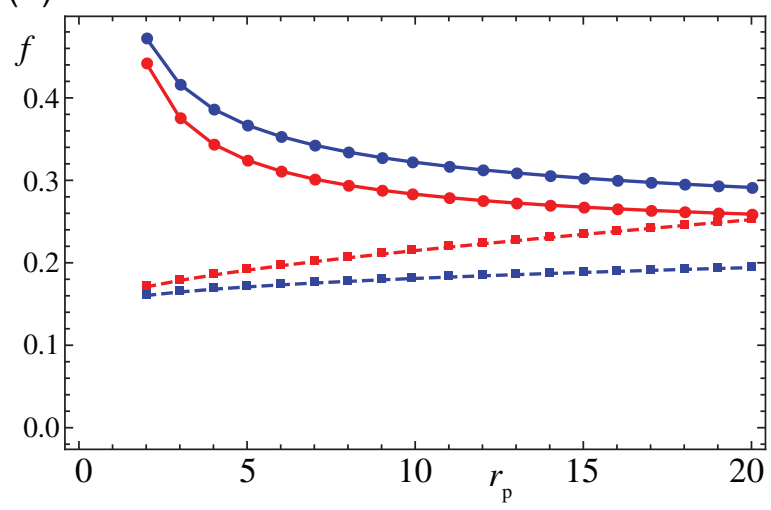

(D)

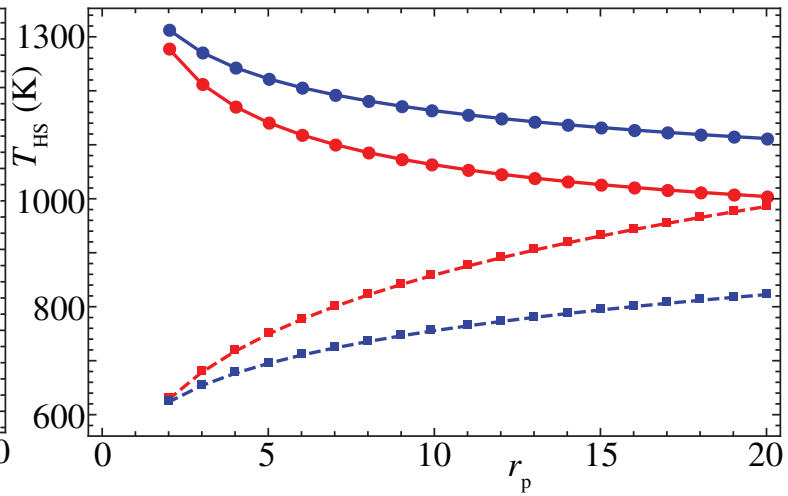

F I G U R E 9 A, Fuel conversion efficiency, $r_{e}$. B, solar share, $f$. C, specific fuel consumption, $\dot{m}_{f}$ (the inset shows a zoom of the recuperative configurations), and $\mathrm{D}$, solar receiver temperature, $T_{H S}$, as functions of the pressure ratio, $r_{p}$ [Colour figure can be viewed at wileyonlinelibrary.com] 
T A B L E 3 Relative variations of some output records with respect to the reference case, $\eta_{\text {DP }}$ (gas turbine Caterpillar Mercury 50 with or without recuperator, $r_{p}=9.9$, project SOLUGAS)

\begin{tabular}{lllllrrr} 
& $\boldsymbol{\eta}_{\text {DP }}$ & $\boldsymbol{r}_{\boldsymbol{p}, \max }$ & $\boldsymbol{\eta}_{\max }$ & \multicolumn{1}{c}{$\boldsymbol{\Delta} \boldsymbol{\eta}$} & \multicolumn{1}{c}{$\boldsymbol{\Delta} \boldsymbol{r}_{\boldsymbol{e}}$} & \multicolumn{1}{c}{$\boldsymbol{\Delta P}$} & \multicolumn{1}{c}{$\boldsymbol{\Delta}$} \\
Dry air (rec.) & 0.296 & 7 & 0.302 & 1.946 & 6.152 & -3.213 & 6.319 \\
Dry air (non-rec.) & 0.224 & 20 & 0.246 & 9.890 & 19.160 & -4.898 & 17.670 \\
$\mathrm{CO}_{2}$ (rec.) & 0.297 & 16 & 0.302 & 1.764 & -3.329 & 8.025 & -6.934 \\
$\mathrm{CO}_{2}$ (non-rec.) & 0.155 & 20 & 0.196 & 26.060 & 29.553 & 18.133 & 7.355
\end{tabular}

Note: $r_{p \text {, max }}$ is the pressure ratio leading to the maximum overall efficiency, $\eta_{\max }$ in each case. Relative variations are shown as percentages. working fluid mass flow and the target turbine inlet temperature. Solar share is higher for the recuperative cases. For these layouts it decreases with $r_{p}$. On the contrary, when no recuperation is considered, $f$ linearly increases with $r_{p}$ (faster for air than for $\mathrm{CO}_{2}$ ). Numerical values of the specific fuel consumption in the combustion chamber are displayed in Figure 9C. Of course fuel consumption is larger for non-recuperative configurations, specially at low pressure ratios. For recuperative configurations, numerical values and qualitative behavior is similar for air and $\mathrm{CO}_{2}$. In both cases there is a quite flat minimum about $r_{p} \simeq 4-6$ where $\dot{m}_{f}$ is below 0.14ton/MWh (see the inset in Figure 9C).

The picture of the solar receiver working temperature, $T_{H S}$, is very interesting (see Figure 9D). Temperatures are much larger for recuperative layouts. They are between $1000 \mathrm{~K}$ (air at $r_{p} \simeq 20$ ) and $1300 \mathrm{~K}\left(\mathrm{CO}_{2}\right.$ at small pressure ratios). On the contrary, the interval in the nonrecuperative cases starts slightly above $600 \mathrm{~K}$ and goes up to $1000 \mathrm{~K}$ (air, non-recuperative). In recuperative layouts $T_{H S}$ decreases with $r_{p}$, and in non-recuperative ones, the behavior is opposite.

Table 3 summarizes the variations of some output records with respect to the reference case (gas turbine Caterpillar Mercury 50 with or without recuperator, $r_{p}=9.9$, project SOLUGAS) for the optimum pressure ratio. Overall plant efficiency was taken as objective function for optimization. It is remarkable the gain simultaneously in all parameters in the case of a power unit working with $\mathrm{CO}_{2}$ in a non-recuperative configuration.

\section{2 | Off-design records}

The model stated in Sec. 2 can be applied to off-design conditions in a straightforward way. Ambient temperature, $T_{L}$, and direct normal irradiance, $G$, are now time dependent parameters. At any time, the working temperature of the solar receiver is calculated by balancing the solar power received from the heliostat field and the heat transferred to the fluid. This leads to time dependent values for the heats, $\dot{Q}_{H}$ and $\dot{Q}_{L}$, and so, to a time dependent efficiency for the heat engine, $\eta_{h}$. With respect to the solar subsystem, optical efficiency associated with the field, $\eta_{0}$, depends on time because of the cosine factor and spillage, that are calculated for each sun position during a day. Heat transfer losses, Equation (5), also evolve with time through the temperatures and $G$. With these elements, overall efficiency or any other thermodynamic parameter result as functions of solar irradiance and ambient temperature, and can be estimated at any hour during a day, at any season. Also yearly averages can be performed.

Off-design analysis is performed for four different days corresponding to the start of each season. Solar field layout was fixed at on-design conditions and computer simulations allow for calculating heliostats efficiency at whichever hour and season. Then, the seasonal variation of heliostats efficiency can be shown in Figure 10 at 16:00 hour (UTC). Particular days were elected without performing any smoothing or averaging. Average field efficiency is largest for winter and smallest for summer, having intermediate values for autumn and spring. Best heliostats in winter have efficiencies between 0.75 and 0.80 and the worst in summer between 0.40 and 0.45 . One should be careful to generalize these results because the meteorological particularities of the selected days were not averaged out.

In Figure 11 hourly evolution of the most representative plant efficiencies for non-recuperative configurations is displayed. Pressure ratios correspond to the best overall efficiencies, as contained in Table 3. Optical efficiency, $\eta_{0}$ and the efficiency of the solar subsystem $\eta_{s}$ (heliostat field and receiver) are similar for both fluids at any season. All other efficiencies are better for air. Heat engine efficiency, $\eta_{h}$, is approximately constant along a day, provided that turbine inlet temperature is fixed and, so, it is mainly influenced by ambient temperature evolution. Nevertheless, overall efficiency, $\eta$, presents a different behavior because it depends on the coupling of the efficiencies of all subsystems, as Equation (1) displays. Particularly, it depends on the efficiencies of the heat engine, $\eta_{h}$, and the solar subsystem, $\eta_{s}$ (heliostat field and receiver with the corresponding optical and heat transfer losses, Equation (5)) because combustion efficiency, $\eta_{c}$, is taken as constant. Overall thermal efficiency, $\eta$, decreases 

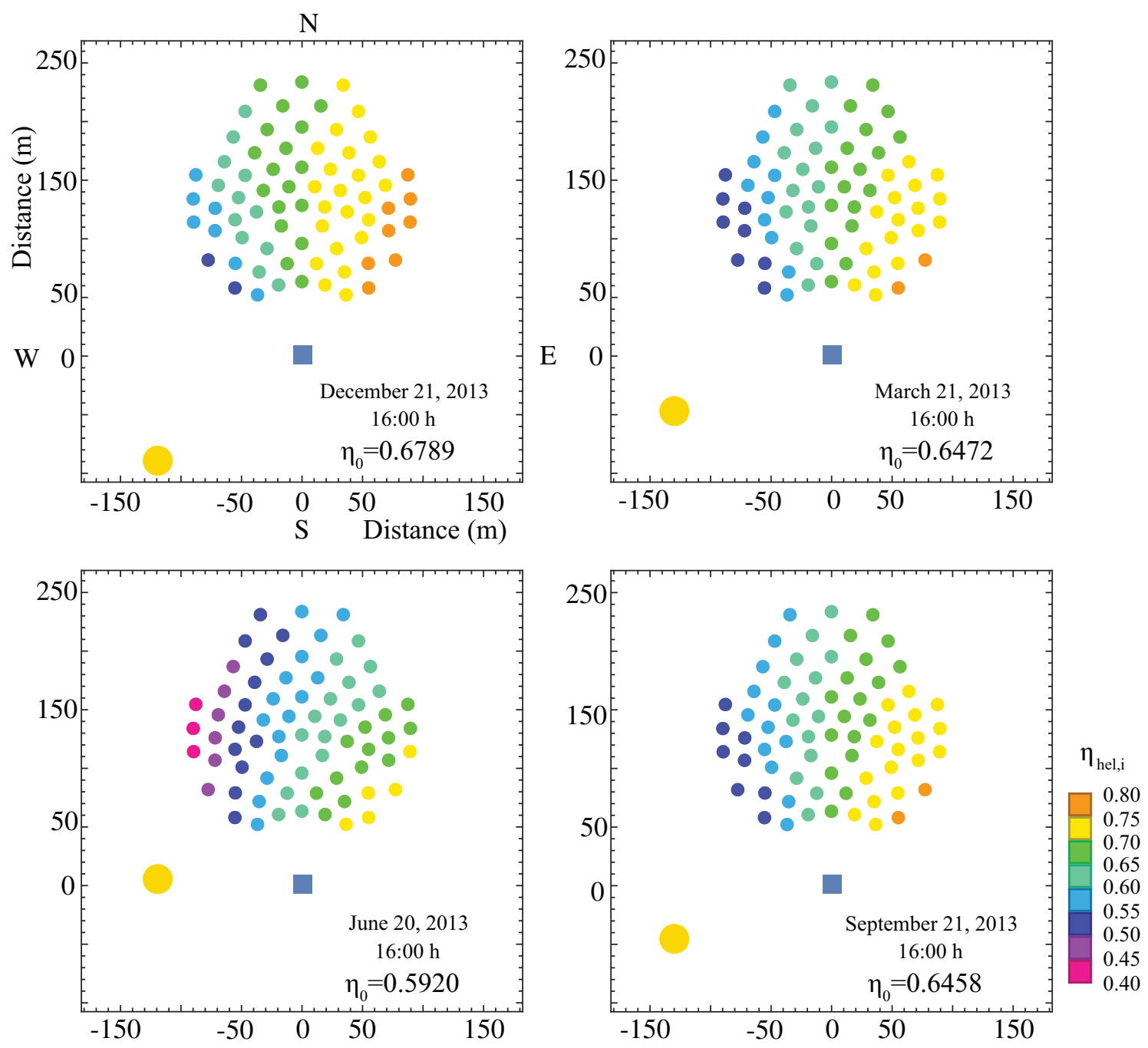

F I G U R E 10 Heliostat efficiencies distribution for representative days of all seasons at 16:00 hour (UTC). Averaged field efficiency, $\eta_{0}$, is displayed in each plot [Colour figure can be viewed at wileyonlinelibrary.com]

during sun hours because the losses coming from the solar subsystem are added to those of the power unit. On the contrary, fuel conversion rate, $r_{e}$ and solar share, $f$, increase. Solar share is always small because of the size of the heliostat field and is always slightly better for air than for $\mathrm{CO}_{2}$. Maximum values are around 0.3 for air during summer.

Daily evolution for the recuperative plant is analyzed through Figure 12 for representative days of each season. All efficiencies and solar share are larger than for the non-recuperative case. Power unit efficiencies, $\eta_{h}$, reach remarkable values, about 0.4 . It is noteworthy that curves for both fluids are very similar. This is because optimum pressure ratios in this case $\left(r_{p, \max }=7\right.$ for air and 16 for $\mathrm{CO}_{2}$ ) lead to almost identical output records (see Table 3 and the dashed horizontal line in Figure 7).

Finally, specific fuel consumption and $\mathrm{CO}_{2}$ emissions (or any other greenhouse emission) can be calculated for any day. Several results are depicted as bar diagrams in Figure 13 for the pressure ratios optimized at design conditions. Of course consumption and emissions are larger for the non-recuperative cases. Approximately, for air emissions are 1.3 times larger in the non-recuperative case and for $\mathrm{CO}_{2}$ the ratio increases up to 1.8. As it happened for the most significant efficiencies, consumption and emissions in recuperative layouts are very similar for both gases. In the absence of recuperation, consumption and emissions are larger for $\mathrm{CO}_{2}$ as consequence of the worse efficiencies of the heat engine (see Figure 11). The small differences between the hybrid mode results and those for the plant working in an only combustion mode result from the relatively undersized dimensions of the solar field.

Note that all off-design calculations have been performed considering the aforementioned optimum 

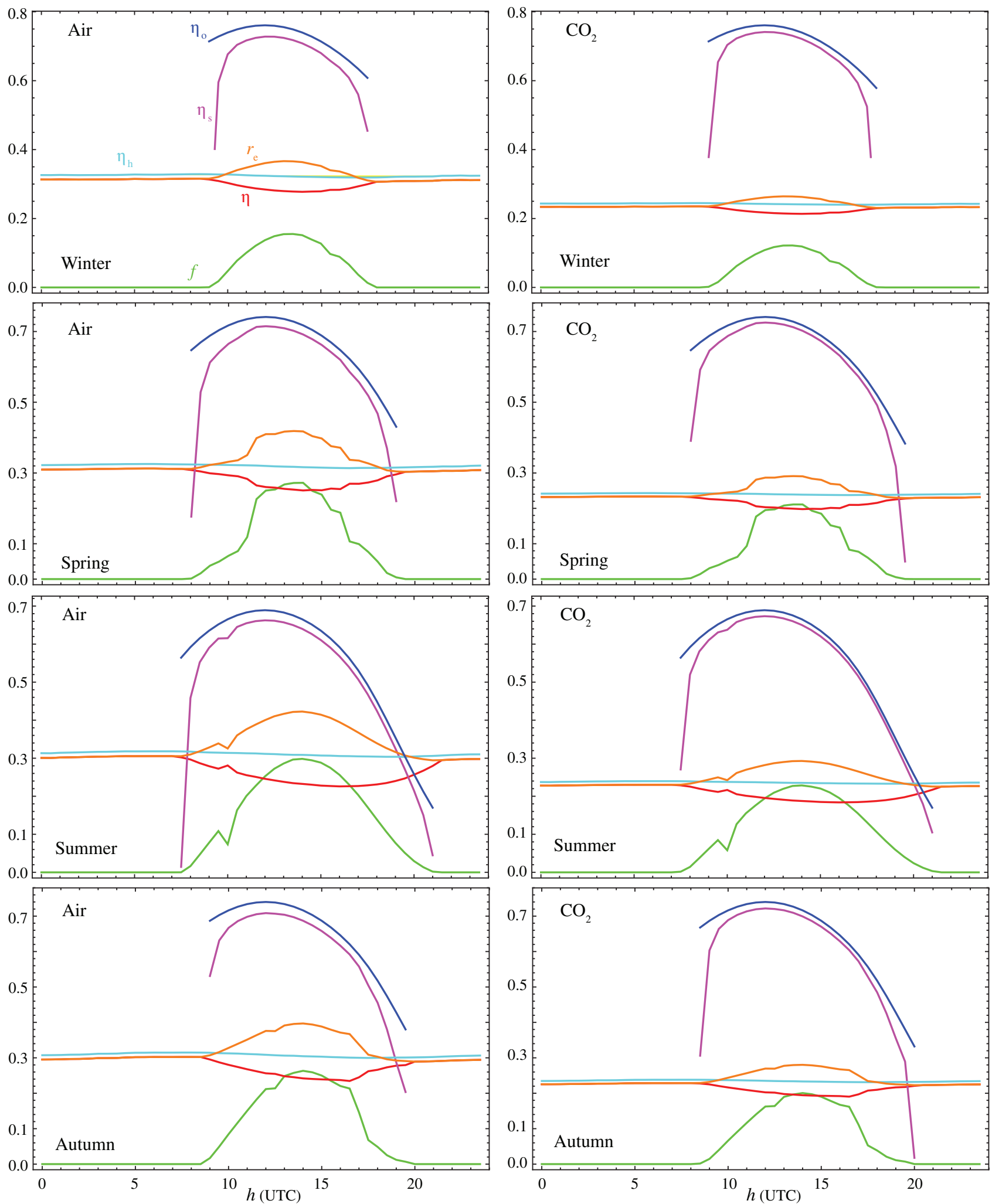

F I G U RE 11 Hourly evolution of the main plant efficiencies and solar share, $f$, for all seasons without recuperation. Working fluids are air (left column) and $\mathrm{CO}_{2}$ (right column). Notation is as follows: solar field optical efficiency, $\eta_{o}$; solar subsystem efficiency (field and receiver), $\eta_{s}$; fuel conversion rate, $r_{e}$; power unit efficiency, $\eta_{h}$; and plant overall efficiency, $\eta$. Pressure ratios were taken from those in Table 3 [Colour figure can be viewed at wileyonlinelibrary.com] 

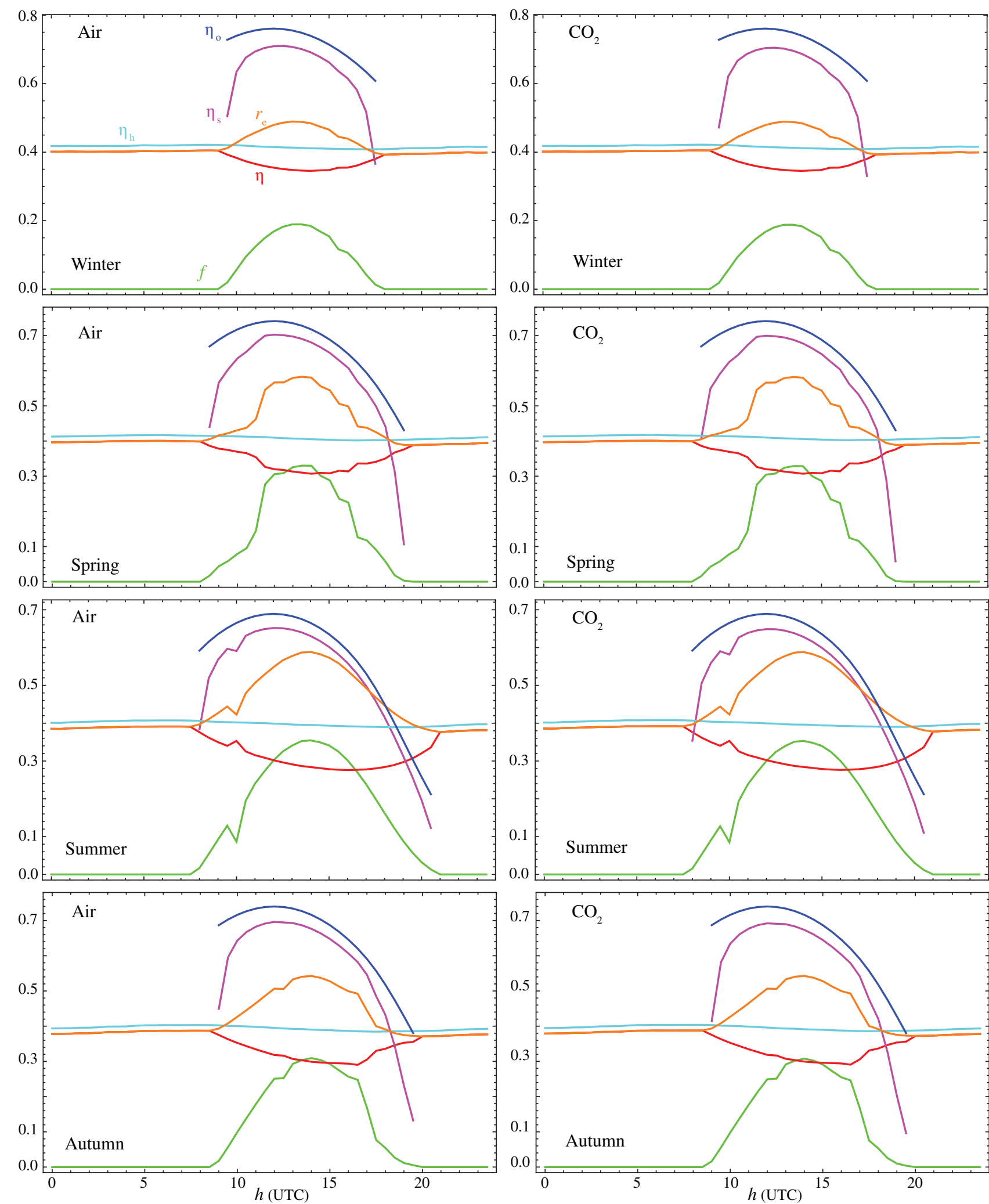

F I G U RE 12 Hourly evolution of the main plant efficiencies and solar share, $f$, for all seasons with recuperation. Working fluids are air (left column) and $\mathrm{CO}_{2}$ (right column). Notation is as follows: solar field optical efficiency, $\eta_{o}$; solar subsystem efficiency (field and receiver), $\eta_{s}$; fuel conversion rate, $r_{e}$; power unit efficiency, $\eta_{h}$; and plant overall efficiency, $\eta$. Pressure ratios were taken from those in Table 3 [Colour figure can be viewed at wileyonlinelibrary.com] 
(A)

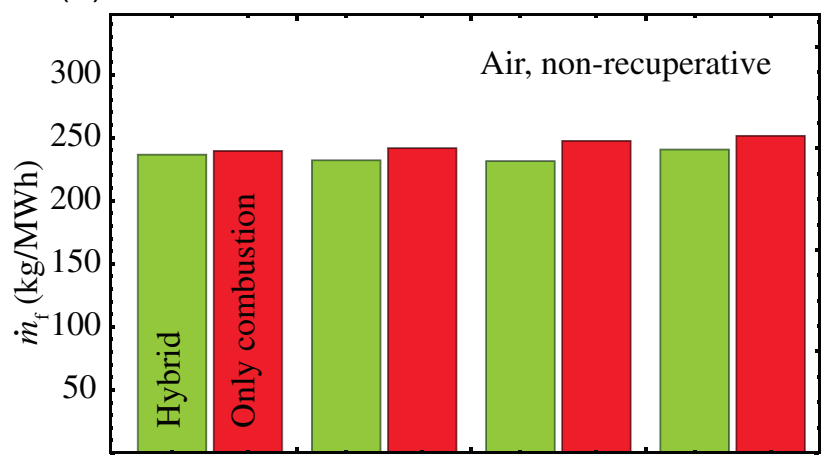

(C)

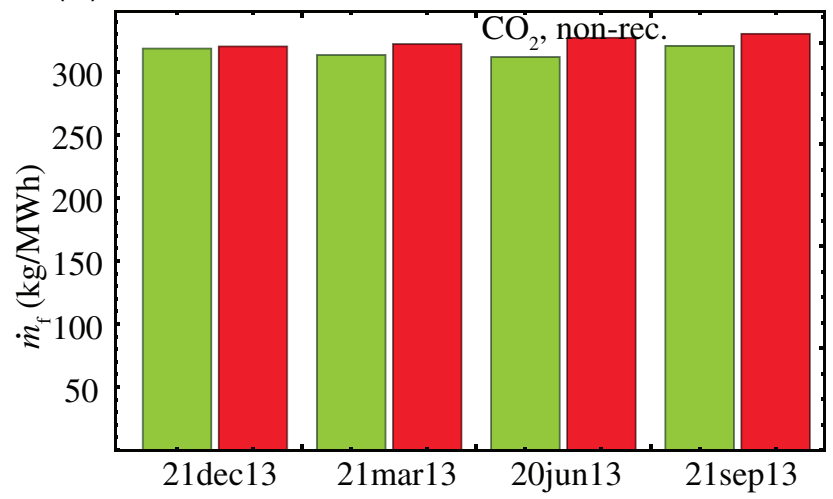

(B)

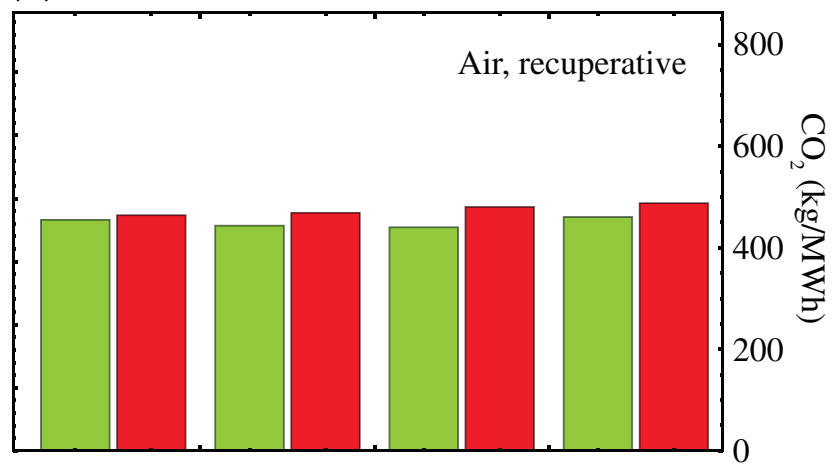

(D)

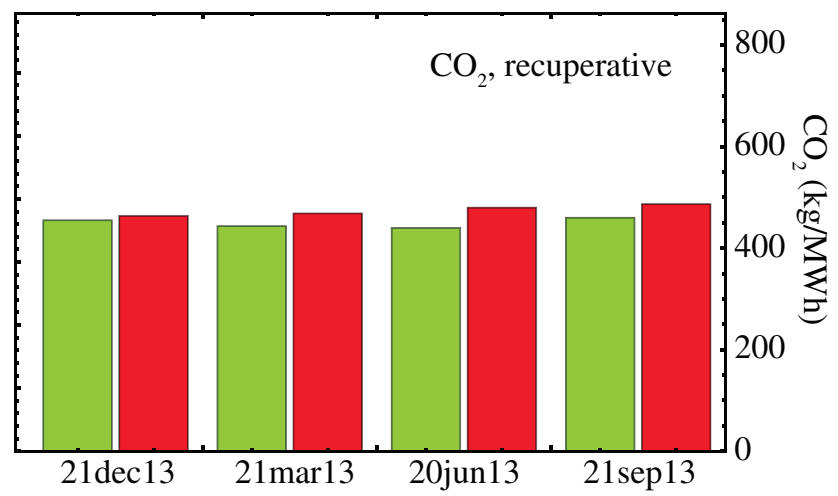

F I G U RE 13 Natural gas consumption and $\mathrm{CO}_{2}$ emissions for the configurations considered for the plant operating in hybrid mode (green bars) or in standard operation, burning natural gas without solar heat input (red ones). A, Working fluid is air and no recuperation is considered. B, air with a recuperator (effectiveness 0.775 ). $\mathrm{C}, \mathrm{CO}_{2}$ without recuperation and $\mathrm{D}, \mathrm{CO}_{2}$ with recuperation $[$ Colour figure can be viewed at wileyonlinelibrary.com]

pressure ratios. The consistency of this election throughout any season and day has been checked. It was concluded that the election of the pressure ratio at on-design conditions is an acceptable choice. Notice that the fuel consumption in Figure 13 is larger than the data contained in Figure 9 because in Figure 13, $\dot{m}_{f}$ is averaged over the whole particular day selected and in the former figure on-design conditions at fixed solar irradiance were considered.

One interesting issue is the influence of the solar field size and shape (small and polar in the case analyzed here) in overall plant efficiency and other records. Recently, our group published another paper for a very much larger field, about 1000 heliostats and a circular field. ${ }^{21}$ Very briefly it could be said that qualitative behavior of efficiencies with the pressure ratio at ondesign conditions, and daily curves at off-design ones are similar in both cases. But numerical differences are important because field optical efficiency is quite larger for fields like the one considered in this paper (compare, for instance, Figure 12 with fig. $15 \mathrm{in}^{21}$ ), and so, overall plant efficiency is fairly higher.

\section{5 | CONCLUSIONS}

A previously developed thermodynamic model for a gas turbine hybridized with a central tower heliostat field has been completed with a comprehensive, but at the same time, reliable solar field submodel, valid for surround (circular symmetry) or polar fields. This model takes into account losses factors as spillage, heliostats blocking and shadowing, and atmospheric attenuation and allows any off-design investigation. Numerical implementation and analysis has been made by taking the dimensions of the solar field and receiver, and the gas turbine parameters from the first prototype pre-commercial plant, called SOLUGAS project (polar field and cavity receiver).

An analysis of plant output variables at design point has been carried out for different working fluids (dry air and carbon dioxide), and for recuperative or nonrecuperative plant layouts. The optimum pressure ratio was estimated for each case taking as objective function the overall plant thermal efficiency. Main subsystems efficiencies were analyzed as a function of the turbine pressure ratio. Maximum achieved overall efficiencies 
were found for air and $\mathrm{CO}_{2}$ when a recuperator is included in plant design (about 0.30), but the pressure ratios for both working fluids are different and also the behavior of different plant records with the pressure ratio as fuel conversion efficiency, solar share, and specific fuel consumption. The latter is, of course, considerable smaller for recuperated configurations. But it is important to notice that the working temperature of the solar receiver is quite higher for those configurations. At optimum pressure ratios temperatures are between $1100-1200 \mathrm{~K}$. These temperatures decrease to $700-900 \mathrm{~K}$ when no recuperator is included in design. The consideration of subcritical $\mathrm{CO}_{2}$ as working fluid has some interesting features: potential for recuperation is higher than for air because turbine outlet temperature is quite higher for $\mathrm{CO}_{2}$, overall efficiency and fuel conversion efficiency have a wider maximum for $\mathrm{CO}_{2}$ when plotted in terms of the pressure ratio (so, the election of the optimum one is less critical), and the solar share is always higher for $\mathrm{CO}_{2}$ in recuperative layouts.

After fixing the optimum pressure ratio at design conditions, an analysis of plant records for any plant subsystem (optical and thermal) was performed for representative days of all seasons. Real meteorological and direct solar irradiance data from SOLUGAS location (south of Spain) were considered, no filtering nor smoothing were done. It is interesting that heliostat field average optical efficiency gets its largest values in winter and the smallest in summer. In the assumed conditions, numerical values fluctuate between approximately 0.59 and 0.68. Overall plant efficiency decreases during sunlight hours because the heliostat field and the receiver add inefficiencies to the whole plant. But at the same time solar share different from zero increases fuel conversion rate and decreases fuel consumption. For all the checked days and seasons heliostat field dimensions of SOLUGAS (about 70 heliostats of $121 \mathrm{~m}^{2}$ each) only allows a small solar share, so the combustion chamber is always burning natural gas to achieve the pre-fixed turbine inlet temperature (about $1420 \mathrm{~K}$ ). The model also allows a detailed calculation of fuel consumption, savings from the non-hybridized plant, and the estimation of any greenhouse or pollutant emissions. For those field dimensions and target turbine inlet temperature specific natural gas consumption (averaged over one representative day) is about $180 \mathrm{~kg} / \mathrm{MWh}$ and $\mathrm{CO}_{2}$ emissions are below $500 \mathrm{~kg} / \mathrm{MWh}$.

The analysis performed in this work reflects the necessity of at least three key actions in order to improve the performance of this technology for commercialization in the next future: (a) to enhance solar field design and efficiency together, (b) to widen the working temperature intervals for the receivers, and (c) to select the most important parameters of the power unit (as the turbine pressure ratio, the working fluid or the consideration of a recuperator) from an overall plant perspective. System versatility is enough to obtain good performance ratios with an appropriate plant design.

\section{ACKNOWLEDGEMENTS}

Financial support from University of Salamanca, Banco Santander, and Junta de Castilla y León of Spain (project SA017P17) is acknowledged.

\section{ORCID}

Alejandro Medina (10) https://orcid.org/0000-0001-97974909

\section{REFERENCES}

1. Weinstein L, Loomis J, Bhatia B, Bierman D, Wang E, Chen G. Concentrating solar power. Chem Rev. 2015;115:12797-12838.

2. Olumayegun O, Wang M, Kelsall G. Closed-cycle gas turbine for power generation: a state-of-the-art review. Fuel. 2016;180: 694-717.

3. Rashid K, Mohammadi K, Powell K. Dynamic simulation and techno-economic analysis of a concentrated solar power plant hybridized with both thermal energy storage and natural gas. J Clean Prod. 2020;248:119193.

4. Okoroigwe E, Madhlopa A. An integrated combined cycle system driven by a solar tower: a review. Renew Sustain Energy Rev. 2016;57:337-350.

5. Burgaleta S, Ramírez DJI. Gemasolar, the First Tower Thermosolar Commercial Plant with Molten Salt Storage. Spain: Granada; 2011.

6. Relloso S, Gutiérrez Y. SENER Molten Salt Tower Technology. Ouarzazate NOOR III Case. Paper presented at: AIP Conference Proceedings, SolarPACES 2016, Abu Dhabi, UAE, Vol 1850. Abu Dhabi, UAE: American Institute of Physics; 2017: 030041.

7. Liu Q, Bai Z, Wang X, Lei J, Jin H. Investigation of thermodynamic performances for two solar-biomass hybrid combined cycle power generation systems. Ener Conv Manage. 2016;122:252-262.

8. Wang K, Li MJ, Guo JQ, Li P, Liu ZB. A systematic comparison of different $\mathrm{S}-\mathrm{CO}_{2}$ cycle layouts based on multi-objective optimization of applications in solar power tower plants. Appl Ener. 2020;212:109-121.

9. Linares JI, Cantizano A, Moratilla BY, Martín-Palacios V, Batet L. Supercritical $\mathrm{CO}_{2}$ Brayton power cycles for DEMO (demonstration power plant) fusion reactor based on dual coolant lithium lead blanket. Energy. 2016;98:271-283.

10. Wang X, Li X, Li Q, Liu L, Liu C. Performance of a solar thermal power plant with direct air-cooled supercritical carbon dioxide Brayton cycle under off-design conditions. Appl Energy. 2020;261:114359.

11. de la Calle A, Bayon A, Soo Too Y. Impact of ambient temperature on supercritical $\mathrm{CO}_{2}$ recompression Brayton cycle in arids locations: finding the optimal design conditions. Energy. 2018; 153:1016-1027.

12. Ma Y, Morosuk T, Luo J, Liu M, Liu J. Superstructure design and optimization on supercritical carbon dioxide cycle for 
application in concentrated solar power plant. Ener Conv Manage. 2020;206:112290.

13. Novales D, Erkoreka A, de la Peña C, Herrazti B. Sensitivity analysis of supercritical $\mathrm{CO}_{2}$ power cycle energy and exergy efficiencies regarding cycle component efficiencies for concentrating solar power. Ener Conv Manage. 2019;182:430-450.

14. Santos MJ, Miguel-Barbero C, Merchán RP, Medina A, Calvo Hernández A. Roads to improve the performance of hybrid thermosolar gas turbine power plants: working fluids and multi-stage configurations. Ener Conv Manage. 2018;165: 578-592.

15. He YL, Cui FQ, Cheng ZD, Zeng-Yao L, Tao WQ. Numerical simulation of solar radiation transmission process for thesolar tower power plant: from the heliostat field to the pressurized volumetric receiver. Appl Therm Eng. 2013;61:583-595.

16. Uhlig R, Flesch R, Gobereit B, Giuliano S, Liedke P. Strategies enhancing the efficiency of cavity receivers. Energ Proc. 2014; 49:538-550.

17. Asselineau C. Geometrical Optimisation of Receivers for Concentrating Solar Thermal Systems [PhD thesis]. Canberra: The Australian National University; 2017.

18. Quero M, Korzynietz R, Ebert M, Jiménez AA, Río dA, Brioso JA. Solugas - operation experience of the first solar hybrid gas turbine system at MW scale. Energ Proc. 2014;49:1820-1830.

19. Korzynietz R, Brioso JA, del Río A, et al. Solugas - comprehensive analysis of the solar hybrid Brayton plant. Sol Ener. 2016; 135:578-589.

20. Merchán RP, Santos MJ, Medina A, Calvo Hernández A. Thermodynamic model of a hybrid Brayton thermosolar plant. Renew Ener. 2018;128:473-483.

21. Merchán RP, Santos MJ, Heras I, Gonzalez-Ayala J, Medina A, Calvo Hernández A. On-design pre-optimization and off-design analysis of hybrid Brayton thermosolar tower power plants for different fluids and plant configurations. Renew Sust Energy Rev. 2020;109590:119. https://doi.org/10. 1016/j.rser.2019.109590.

22. Duffie J, Beckman W. Solar Engineering of Thermal Processes. Hoboken, New Jersey: John Wiley and Sons; 2006.

23. Li C, Zhai R, Liu H, Yang Y, Wu H. Optimization of a heliostat field layout using hybrid PSO-GA algorithm. 2018; 128: 33-41.

24. Zhang M, Yang L, Xu C, Du X. An efficient code to optimize the heliostat field and comparisons between the biomimetic spiral and stagerred layout. Renew Ener. 2016;87:720-730.
25. Collado FJ. Preliminary design of surrounding heliostat fields. Renew Ener. 2009;34:1359-1363.

26. Collado FJ, Guallar J. A review of optimized design layouts for solar power tower plants with campo code. Renew Sustain Energy Rev. 2013;20:142-154.

27. Solar, Turbines, Caterpillar.

28. Olivenza-León D, Medina A, Calvo Hernández A. Thermodynamic modeling of a hybrid solar gas-turbine power plant. Energ Conv Manage. 2015;93:435-447.

29. Meteosevilla. http://www.meteosevilla.com. Accessed August 1, 2020.

30. Santos MJ, Merchán RP, Medina A, Calvo Hernández A. Seasonal thermodynamic prediction of the performance of a hybrid solar gas-turbine power plant. Ener Conv Manage. 2016; 115:89-102.

31. Lemmon EW, Huber ML, McLinden MO. NIST Standard Reference Database 23: Reference Fluid Thermodynamic and Transport Properties-REFPROP, Version 9.1. Gaithersburg: National Institute of Standards and Technology, Standard Reference Data Program; 2013.

32. Luu MT, Milani D, McNaughton R, Abbas A. Dynamic modelling and start-up operation of a solar-assisted recompression supercritical $\mathrm{CO}_{2}$ Brayton power cycle. Appl Ener. 2017;199: 247-263.

33. Crespi F, Gavagnin G, Sánchez D, Martínez GS. Supercritical carbon dioxide cycles for power generation. Appl Ener. 2017; 195:152-183.

34. Coco-Enríquez L, Muñoz-Antón J, Martínez-Val JM. New text comparison between $\mathrm{CO}_{2}$ and other supercritical working fluids (ethane, $\mathrm{Xe}, \mathrm{CH}_{4}$, and $\mathrm{N}_{2}$ ) in line-focusing solar power plants coupled to supercritical Brayton power cycles. Int $J$ Hydrogen Ener. 2017;42:17611-17631.

35. Stine WB, Geyer M. Power from The Sun. 2001.

How to cite this article: Merchán RP, Santos MJ, Medina A, Hernández AC. On- and off-design thermodynamic analysis of a hybrid polar solar thermal tower power plant. Int J Energy Res. 2020; 1-17. https://doi.org/10.1002/er.5854 